\title{
Investigations and management strategies of acute myocardial infarction in young adults (a single centre clinical audit)
}

\author{
Authors: Shkaar Affandi ${ }^{\mathrm{A}}$ and Sean O'Nunain ${ }^{\mathrm{A}}$
}

\section{Introduction}

Myocardial infarction (MI) is one of the leading causes of death in the world and is generally considered a disease of older people. ${ }^{1,2}$ Recent data, however, show that the disease among young adults, though not common, accounts for 1 in 20 of all acute myocardial infarction (AMI) cases. ${ }^{3-6}$ The management of this patient cohort has not been well categorised. This study, therefore, audited the investigation and treatment of patients aged $\leq 45$ years presenting with AMI to a tertiary cardiac centre over a 15 -year period. The aim was to answer whether all patients underwent invasive investigation, all patients received appropriate secondary preventive drugs, and systematic investigation was undertaken to detect less common causes of AMI in the $\leq 45$ year age group.

\section{Materials and methods}

A secondary data analysis method was employed, using the data stored on the MINAP database for 7,455 patients presenting with an AMI to the Royal Sussex County Hospital between 2013 and 2018. ${ }^{6,7}$ Patients presenting with a first AMI $(5,776)$ were divided into two groups: Group $1 \leq 45$ years and Group 2 $\geq 46$ years. Full demographics, risk factors, investigations and treatment were analysed for both groups. In addition, detailed analysis was performed in the last 50 consecutive patients in Group 1 with review of angiographic films, echocardiographic images and medication dosage on discharge.

\section{Results}

Of all patients admitted with MI, 376 were $\leq 45$ years old ( $62 \%$ were $41-45,27 \%$ were $36-40$ and $11 \%$ were $30-35$ ). Eighty per cent had a smoking history, $47.1 \%$ had a positive family history of MI and the mean body mass index (BMI) was $29.27 \pm 13.07 \mathrm{~kg} / \mathrm{m}^{2}$. The most common previous medical conditions were hypertension (21.3\%), hypercholesterolaemia (17\%) and diabetes $(7.7 \%)$. The troponin level was raised in $95.93 \%$, and $75.5 \%$ had ST segment elevation on presentation. The commonest culprit lesion was the left anterior descending artery (50\%), and 56\% had single vessel disease (SVD). The mean left ventricular ejection fraction before primary coronary intervention (PCI) was $46.9 \pm 9.5 \%$ and on average improved by $10 \%$ post-PCI. Only one patient was screened for patent foramen ovale (PFO) using echocardiography with bubble study. Only $16 \%$ had been screened for clotting abnormalities. On discharge, $72 \%$ of the patients were given all appropriate medication. Twelve per cent had not been given any antiplatelet agent, whereas the most common antiplatelet regimen was aspirin with clopidogrel. The usual prescribed angiotensin-converting enzyme inhibitor/ angiotensin receptor blocker was ramipril; 60\% received either ramipril $1.25 \mathrm{mg}$ or $2.5 \mathrm{mg}$. Bisoprolol was the typical prescribed beta blocker; $54 \%$ were prescribed bisoprolol $1.25 \mathrm{mg}$ or $2.5 \mathrm{mg}$. Eighty-four per cent were administered a statin, with the most common prescription $(70 \%)$ being atorvastatin $80 \mathrm{mg}$.

\section{Conclusions}

Our results show that the majority of young patients with MI underwent appropriate invasive investigations and revascularisation, with $92 \%$ having TIMI 3 flow in the culprit coronary lesion post-intervention. Almost all young patients post-MI diagnosis received all appropriate secondary prevention drugs, but contrary to the National Institute for Health and Care Excellence guidelines not all patients received all four types of preventive drugs, and those who were prescribed these drugs did not receive optimal doses. Furthermore, investigation for clotting abnormalities and PFO had been performed in only a small number of patients.

\section{Conflicts of interest}

None declared.

\section{References}

1 World Health Organization. The top 10 causes of death. WHO, 2017.

2 British Heart Foundation. Cardiovascular disease statistics - BHF UK factsheet. BHF, 2017.

3 Tungsubutra W, Tresukosol D, Buddhari W et al. Acute coronary syndrome in young adults: the Thai ACS Registry. J Med Assoc Thai 2007;90(Suppl 1):81-90.

4 Panduranga P, Sulaiman K, Al-Zakwani I, Abdelrahman S. Acute Coronary Syndrome in Young Adults from Oman: Results from the Gulf Registry of Acute Coronary Events. Heart Views 2010;11:93-8.

5 Teixeira M, Sa I, Mendes JS, Martins L. Acute coronary syndrome in young adults. Rev Port Cardiol 2010;29:947-55.

6 Boslaugh S. Secondary data sources for public health: A practical guide. Cambridge: Cambridge University Press, 2007.

7 Johnston MP. Secondary data analysis: A method of which the time has come. Qualitative and Quantitative Methods in Libraries 2014;3:619-26. 